\title{
Thermoanalytical studies of the ceramic-metal composites obtained by gel-centrifugal casting
}

\author{
Justyna Zygmuntowicz ${ }^{1}$ - Paulina Wiecinska ${ }^{2}$ Aleksandra Miazga ${ }^{1}$. \\ Katarzyna Konopka ${ }^{1} \cdot$ Mikolaj Szafran $^{2} \cdot$ Waldemar Kaszuwara ${ }^{1}$
}

Received: 23 May 2017/Accepted: 12 August 2017/Published online: 24 August 2017

(c) The Author(s) 2017. This article is an open access publication

\begin{abstract}
Composite material with a gradient concentration of the metallic phase was prepared by the novel gelcentrifugal casting method. This method combines the consolidation of powders by the centrifugal force with the reaction of radical polymerization of an organic monomer which simultaneously proceeds within the composite slurry. The combination of the centrifugal casting with gelcasting permits production of ceramic-metal composites, including materials with a gradient distribution of metallic particles in a ceramic matrix. Special attention was paid to the thermal analysis of the composite $\mathrm{Al}_{2} \mathrm{O}_{3}-\mathrm{Ni}$ green bodies and the binder used in the fabrication of the material. The experiments were performed on the simultaneous thermal analyzer coupled with the mass spectrometer. The measurements were carried out in air and the inert atmosphere (argon) what allowed to determine the effects characteristic for organic binder decomposition and type of gases released to the atmosphere during thermal treatment. The measurements allowed also to establish the sintering program of the green composite samples and evaluate whether harmful gases are released to the atmosphere. The thermal experiments were complemented with physical and structural measurements, including $\mathrm{X}$-ray diffraction and scanning electron microscopy.
\end{abstract}

Justyna Zygmuntowicz

justyna.zygmuntowicz@inmat.pw.edu.pl

1 Faculty of Materials Science and Engineering, Warsaw University of Technology, 141 Woloska St, 02-507 Warsaw, Poland

2 Faculty of Chemistry, Warsaw University of Technology, 3 Noakowskiego St, 00-664 Warsaw, Poland
Keywords Gel-centrifugal casting · Ceramic-metal composite $\cdot$ Thermal analysis $\cdot \mathrm{Al}_{2} \mathrm{O}_{3}-\mathrm{Ni} \cdot$ Mass spectrometry

\section{Introduction}

Colloidal shaping of ceramic and composite materials plays recently much attention due to the possibility of obtaining homogenous components of different geometries without using high-pressure apparatus [1-3]. The concept of gel-casting, belonging to shaping methods based on colloidal processes, was first presented by researchers from Oak Ridge National Laboratory in 1990 [4, 5]. This method is a well-known colloidal technique in the preparation of high-quality, complex-shape, tough green bodies by means of polymerization of organic monomers in the ceramic suspensions [6-10]. The method does not require the use of sophisticated equipment as in case of injection molding [4]. Gel-casting method allows also manufacturing metal parts [11], ceramic matrix composites such as zirconia-toughened alumina (ZTA) [12], or ceramic-metal composites [13]. Among forming methods which allow obtaining the composites with the gradient distribution of metallic particles, magnetic field-induced sedimentation [14] or centrifugal slip casting (CSC) [15] can be mentioned. The gradient distribution of different phases in composite materials can be achieved through cold-pressing and lamination [16] as well as in the form of thin coatings [17].

In the case of the method using the magnetic field-induced sedimentation, the gradient is dependent on the ferromagnetic properties of metallic powders. The powders which do not have such properties will not be set in motion by the action of the magnetic field which results in obtaining a composite without any gradient. In addition, 
the limitation of this method is the difficulty in production of large-size components because of the limited use of the range of magnetic field.

The centrifugal slip casting (CSC) combines the effects of slip casting and centrifugation [15, 18-20]. The use of porous gypsum molds in the CSC method allows the removal of the liquid medium from the slurry what leads to densification of the composites. Additionally, the use of centrifugal force causes the simultaneous variable deployment of the metal particles in a ceramic matrix. Previous own research has shown that in centrifugal slip casting method lower value of centrifugal acceleration can be applied than in the classical method of centrifugal casting of the composites with the metal matrix [15, 19]. This technology allows to obtain the finished product in the shape of a hollow cylinder [15, 18-20] characterized by high relative density after sintering.

It was noticed in the scientific literature that the materials obtained by centrifugal casting are less defected in comparison with materials formed by uniaxial or isostatic pressing [21-23]. It was also observed that the use of centrifugal force may result in the removal of gas bubbles (which can adsorb on the surface of powders and agglomerate during the preparation and mixing of slurry), so thus it is not necessary to further degas slurries by using a vacuum pump. Lack of bubbles also improves the quality of the components in the green state. Open porosity is reduced, and the quality of sample surface is high; therefore, additional machining is not required [22].

In the centrifugal slip casting method, a porous gypsum mold is used which removes a liquid medium during forming of the composites. Centrifugal slip casting method enables the production of axially symmetric composites. So far, studies have revealed that the resulting composites are composed of three different zones differing in the content of the metallic phase [15, 18-20]. It was observed that the outer part of the graded region was formed as a result of removing water by the capillary forces active in the gypsum mold. This zone in each case was characterized by a value equal to the content of the reinforcement of the metallic phase in the initial slurry. The maximum amount of metal particles was observed in the central region of composites. This part of the sample was formed due to the centrifugal acceleration combined with the capillary action. The metal content decreases continuously from a maximum value to zero in the inner part of samples. Own research showed the characteristic sharp transitions between zones in obtained composites. This is not preferred in many applications. More preferred, however, is the situation when the maximum content of the metallic phase is in the outer part of the element.

In the present work, functional graded materials were fabricated using gel-centrifugal casting. This method combines the consolidation of powders by the centrifugal force with the reaction of radical polymerization of and organic monomer which simultaneously proceeds within the composite slurry. The combination of the centrifugal casting with gel-casting permits producing ceramic-metal composites like $\mathrm{Al}_{2} \mathrm{O}_{3}-\mathrm{Ni}$, including materials with a gradient of particles concentration. This technique can be used for producing sleeve-shaped parts with a gradient concentration of metallic phase intended to, e.g., transporting of toxic media.

\section{Experimental}

The starting powders were: $\alpha-\mathrm{Al}_{2} \mathrm{O}_{3}$ of the average particle size of $0.1 \mu \mathrm{m}$ and density $3.96 \mathrm{~g} \mathrm{~cm}^{-3}$ (TM-DAR, Taimei Chemicals) and nickel powder of the average particle size of $27 \mu \mathrm{m}$ and density $8.9 \mathrm{~g} \mathrm{~cm}^{-3}$ (Sigma-Aldrich). Citric acid (CA) (Sigma-Aldrich) and diammonium hydrocitrate (DAC) (Sigma-Aldrich) were applied as dispersants in the composite slurries. The selection of dispersant was made based on previous research [18, 24, 25]. Deionized Milli-Q water was used as a solvent. The glycerol monoacrylate (GM) was used as a monomer. The monomer has been synthesized at the Faculty of Chemistry Warsaw University of Technology from acrylic acid and glycerol [26]. As the redox type initiator of polymerization the system ammonium persulfate APS (Sigma-Aldrich) $-N, N, N^{\prime}, N^{\prime}$-tetramethylethylenediamine TEMED (Sigma-Aldrich) was used. The initiator was used in the form of $10 \%$ aqueous solution.

The first step in producing of ceramic-metal composites with a gradient distribution of the metallic particles by gelcentrifugal casting technique was the preparation of the slurry. The aqueous ceramic slurries contained $50 \mathrm{vol} \%$ of solid phase including $10 \mathrm{vol} \%$ of the $\mathrm{Ni}$ particles with respect to the total solid volume. The concentrations of $\mathrm{CA}$, DAC and GM, equaled respectively $0.1,0.3$ and 4.0 mass \% with respect to solid phase, while the concentrations of TEMED and APS equaled 0.5 and 3 mass $\%$ with respect to monomer content. The slurries were mixed in a PM 200 planetary ball mill (Retsch), for $1 \mathrm{~h}$ at the rate of $300 \mathrm{rpm}$. Then, the aqueous ceramic slurries were degassed in a device for automatic slurry mixing and degassing-ARE-250 produced by Thinky Corporation for $3 \mathrm{~min}$ at the rate of $1500 \mathrm{rpm}$. Degassing step was applied to prevent oxygen inhibition of the polymerization process. Next, the initiator of the polymerization was added to the slurry. After the initiator was added to the suspensions, the slips were again placed in the ARE-250 device so as to be mixed with the initiator $\left(30 \mathrm{~s} 900 \mathrm{rpm}^{-1}\right.$ ). Just after stirring the slurries with the initiator, the slurries were casted into a Teflon mold. The dimensions of the Teflon mold were as follows: the outer radius $-40 \mathrm{~mm}$, length- 
$60 \mathrm{~mm}$, the thickness- $10 \mathrm{~mm}$, and the inner radius$20 \mathrm{~mm}$. Then, the tubular mold was centrifuged in the radial direction with the $1700 \mathrm{rpm}$ for $1 \mathrm{~h}$. Previous own research has shown that the use of centrifugal force may result in the removal of gas bubbles which can adsorbed on the surface of powders and agglomerate during the preparation and mixing of the slurry. After the centrifugation, the specimen was removed from the Teflon mold and dried at $30{ }^{\circ} \mathrm{C}$ for $24 \mathrm{~h}$. Then, the samples were sintered at $1400{ }^{\circ} \mathrm{C}$ in the reducing atmosphere $\left(\mathrm{H}_{2} / \mathrm{Ar}\right)$. During the sintering, the heating and cooling rate were $2{ }^{\circ} \mathrm{C} \mathrm{min}{ }^{-1}$.

The phase identification of the samples was conducted by X-ray diffraction (Rigaku MiniFlex II) using $\mathrm{CuK} \alpha_{1.54}$ radiation and $\lambda=1.54178 \AA$. Terms of record: voltage $30 \mathrm{kV}$, current $15 \mathrm{~mA}$, angular range 2 Theta $20^{\circ}-100^{\circ}$, step $0.02^{\circ}$, and counting time $0.5 \mathrm{~s}$ on the surface of samples. The results were obtained in the form of plots of the diffracted intensities as a function of 2Theta.

The density of the sintered samples was calculated from the data obtained by the Archimedes method, according to the European Standard EN623-2. The theoretical density used to determine relative density was calculated from the rule of mixtures.

DTA/TG/MS measurements have been performed for the pure polymer obtained from glycerol monoacrylate and for the $\mathrm{Al}_{2} \mathrm{O}_{3}-\mathrm{Ni}$ green bodies obtained by gel-centrifugal casting. DTA/TG measurements were carried out by using a Netzsch STA Jupiter 449C coupled with a quadrupole mass spectrometer Netzsch QMS 403C. The heating rate was $5{ }^{\circ} \mathrm{C} \min ^{-1}$; the final temperature was $1000{ }^{\circ} \mathrm{C}$. The measurements were performed in two atmospheres: oxidizing of synthetic air $\left(80: 20 \mathrm{~N}_{2}: \mathrm{O}_{2}\right)$ and neutral of argon, both in the flow of $60 \mathrm{~mL} \mathrm{~min}{ }^{-1}$. The mass spectrometer was set to detect $m / z$ values in the mass range 10-300. The quantities of polymeric samples taken to measurements equaled from 0.1 to $0.2 \mathrm{~g}$. These samples have been covered by calcinated (non-reactive) $\mathrm{Al}_{2} \mathrm{O}_{3}$ powder in the quantity of $0.3 \mathrm{~g}$ in order to prevent the polymer creeping from the crucible. The $\mathrm{Al}_{2} \mathrm{O}_{3}-\mathrm{Ni}$ green bodies have been placed in crucibles without any coverage. The precise simulation of the sintering processes $\left(1400{ }^{\circ} \mathrm{C}\right.$; the reducing atmosphere of $\left.\mathrm{H}_{2} / \mathrm{Ar}\right)$ is at the moment impossible due to the specific construction of the apparatus; however, the comparison of thermal behavior of the substances with and without the presence of the oxygen brings also valuable information.

The microstructure and gradient distribution of particles of cross section of composites were observed by means of a SU-70 scanning electron microscope. For these purposes, the samples were first sectioned and then prepared with the standard metallographic technique (grinding and polishing with diamond suspensions up to $1 \mu \mathrm{m}$ ).

Stereological analysis has been described quantitatively with the use of a computer image analyzer equipped with the Micrometer program [27]. This technique allows obtaining information about the distribution of metallic phases in the material. Quantitative description of the microstructure included: image processing, measurements, and interpretation of obtained results. The analysis was based on the SEM micrographs of randomly selected areas positioned on a cross section of the sample [28, 29]. Microstructure observations were performed using magnification $500 \times$. The average values were calculated from measurement of 30 images.

Vickers hardness was measured on MetaServ 250 grinder-polisher, Buehler, the polished surface with the given load of $98 \mathrm{~N}$ with $10 \mathrm{~s}$ holding time.

\section{Results and discussion}

Thermogravimetry is a very useful tool to determine decomposition stages of different organic and inorganic substances [29, 30]. Additionally, the possibility of coupling the apparatus with MS or FTIR spectrometers allows to gain new knowledge about decomposition products of samples during thermal treatment $[31,32]$. DTA, TG, and DTG curves and the data from the mass spectrometer for the pure polymer obtained from glycerol monoacrylate measured in air are shown in Fig. 1. The total mass loss was $94.8 \%$ and was observed from ca. $95^{\circ} \mathrm{C}$ till ca. $599{ }^{\circ} \mathrm{C}$. Three stages of polymer (binder) degradation were observed: the first stage till $245{ }^{\circ} \mathrm{C}$ connected with $15.7 \%$ mass loss, the second stage till $436{ }^{\circ} \mathrm{C}$ with $57.7 \%$ mass loss, and the third stage till $599{ }^{\circ} \mathrm{C}$ with $21.7 \%$ mass loss. The mass spectrometer has detected two $\mathrm{m} / \mathrm{z}$ values of relatively high intensities: 18,44 , and two $\mathrm{m} / \mathrm{z}$ values of low intensities: 45 and 46 . Mass 18 can be ascribed to water vapor, while mass 44 to carbon dioxide [33]. Masses 45 and 46 may come from the low-chain $\left(C_{3}\right.$ and $\left.C_{4}\right)$ hydrocarbons [34]. The thermal degradation of poly(glycerol monoacrylate) in air is connected with one exothermic peak with two maxima at 448.6 and $536.5^{\circ} \mathrm{C}$. In these temperatures, the significant increase in the intensities of $\mathrm{m} / \mathrm{z}$ values is observed. No carbon residues were observed in the crucible after the measurement.

A little different behavior was observed for poly(glycerol monoacrylate) heated in non-oxidizing atmosphere, argon (Fig. 2). The total mass loss was $92.9 \%$ and was observed from ca. $100{ }^{\circ} \mathrm{C}$ till ca. $900{ }^{\circ} \mathrm{C}$; however, the mass spectrometer has detected no signals above $500{ }^{\circ} \mathrm{C}$. Three stages of polymer degradation were observed as in the case of measurement carried out in air, but the main degradation step can be ascribed to the lower temperature range $173-266{ }^{\circ} \mathrm{C}$ connected with $61.8 \%$ mass loss. The intensive increase in most of the MS signals is also observed in the $240-245{ }^{\circ} \mathrm{C}$ temperature range. The mass 
(a)

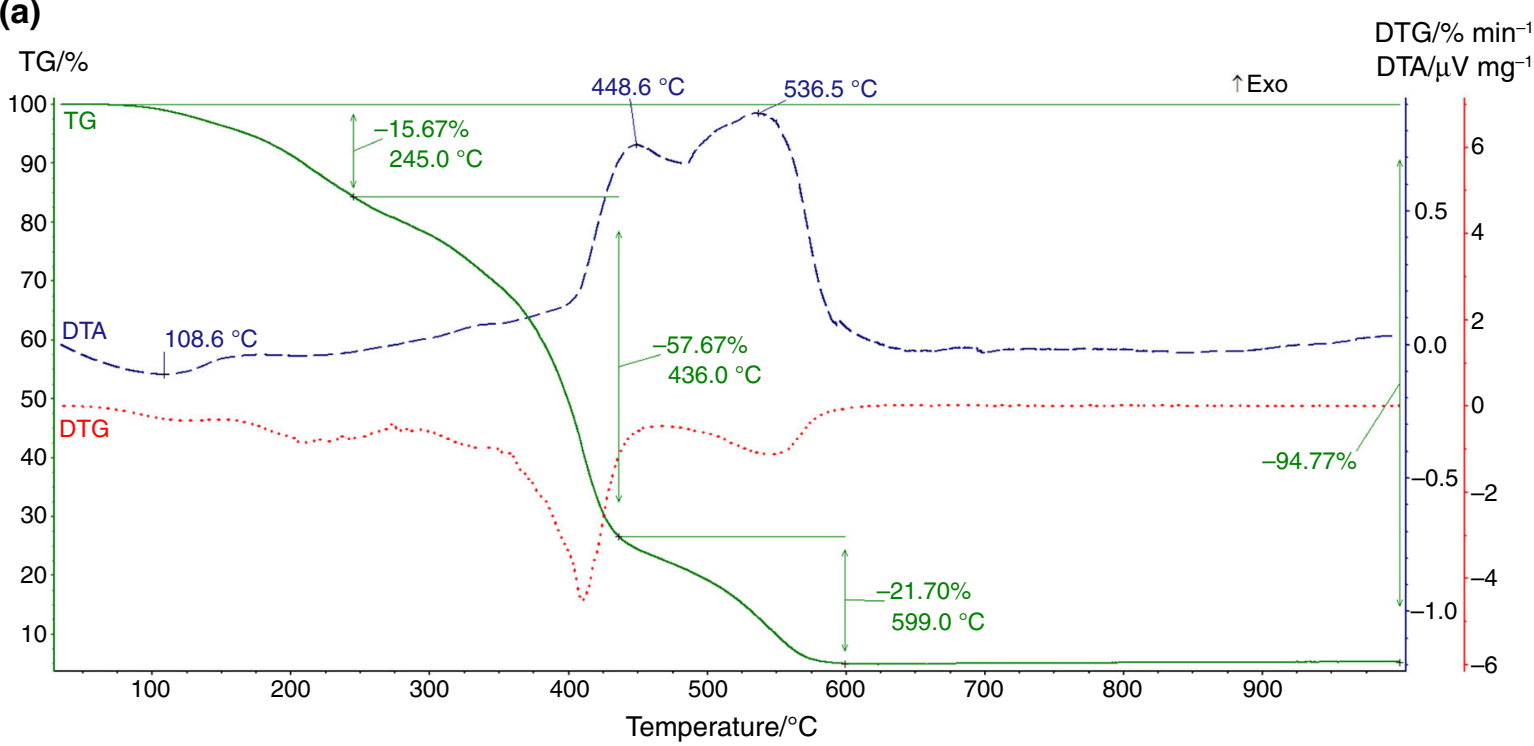

(b)

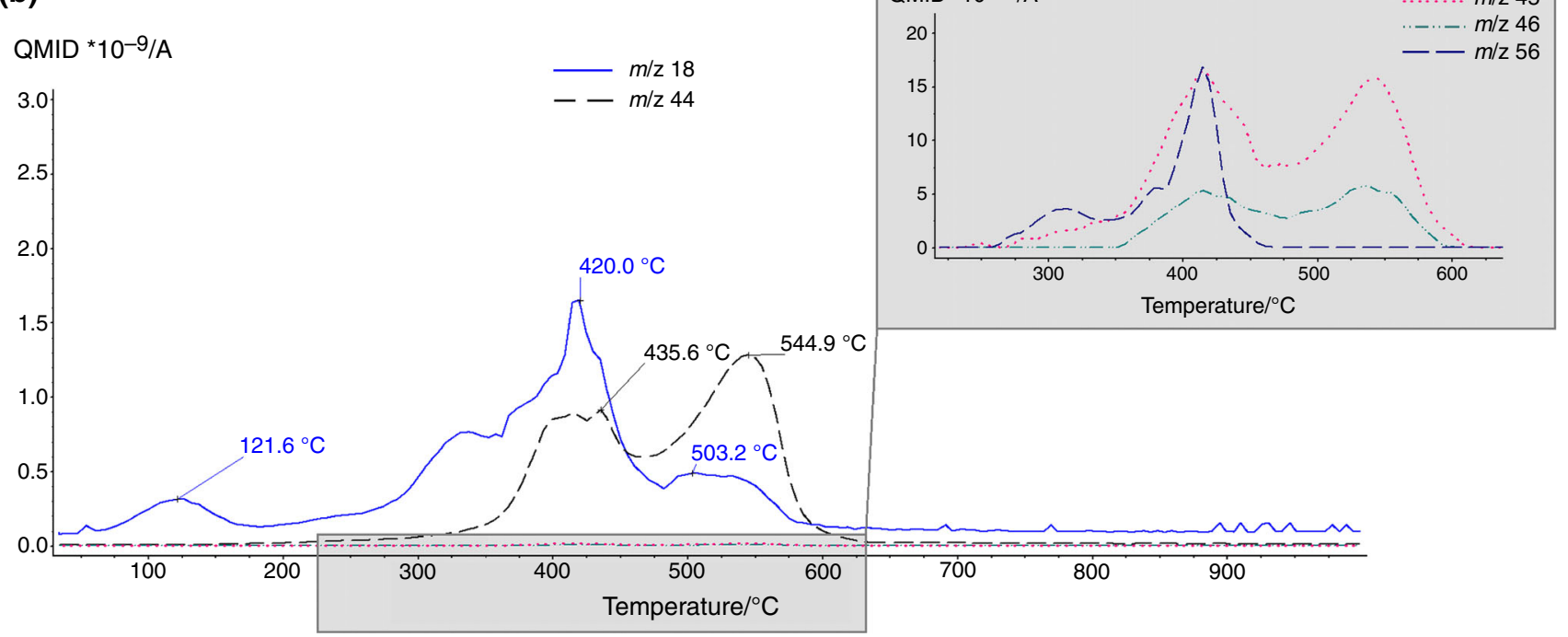

Fig. 1 a DTA/TG/DTG curves of poly(glycerol monoacrylate) registered in oxidizing atmosphere (air); b data from the mass spectrometer coupled with TG

spectrometer has detected five $m / z$ values: $16,18,44,45$, and 72 . Mass 72 may refer to C5 hydrocarbons, while mass 16 to oxygen. In case of the measurements carried out in air atmosphere, it is impossible to observe any changes on $\mathrm{m} / \mathrm{z}$ values corresponding to $\mathrm{O}$ and $\mathrm{N}$ molecules because the intensities of signals coming from air as for the measuring gas are few times higher than for gases released from samples. Therefore, in case of the measurements conducted in argon, one can observe the temperature regions at which oxygen appears. The main conclusion based on the comparison of the measurements carried out in oxidizing and non-oxidizing atmosphere is that in case of the presence of argon degradation of poly(glycerol monoacrylate) proceeds faster. On the other hand, some amounts of carbon residues remain in crucible.
The important question was whether thermal degradation of the binder proceeds in the same way from the $\mathrm{Al}_{2} \mathrm{O}_{3}-\mathrm{Ni}$ green body. The measurements of $\mathrm{Al}_{2} \mathrm{O}_{3}-\mathrm{Ni}$ samples obtained by gel-centrifugal casting with the use of glycerol monoacylate as the monomer have been performed again in oxidizing and non-oxidizing atmosphere. The obtained results show that the presence of ceramic and metallic powders has some influence on the degradation process of organics. For measurements carried out in air (Fig. 3), the mass loss equaling $5.4 \%$ is observed till $505{ }^{\circ} \mathrm{C}$, while with the further temperature increase, the mass increase of $4.3 \%$ is observed, as expected. The mass loss at lower temperatures is connected with thermal decomposition of organic additives used in gel-centrifugal casting, mainly poly(glycerol monoacrylate). However, the 
(a)

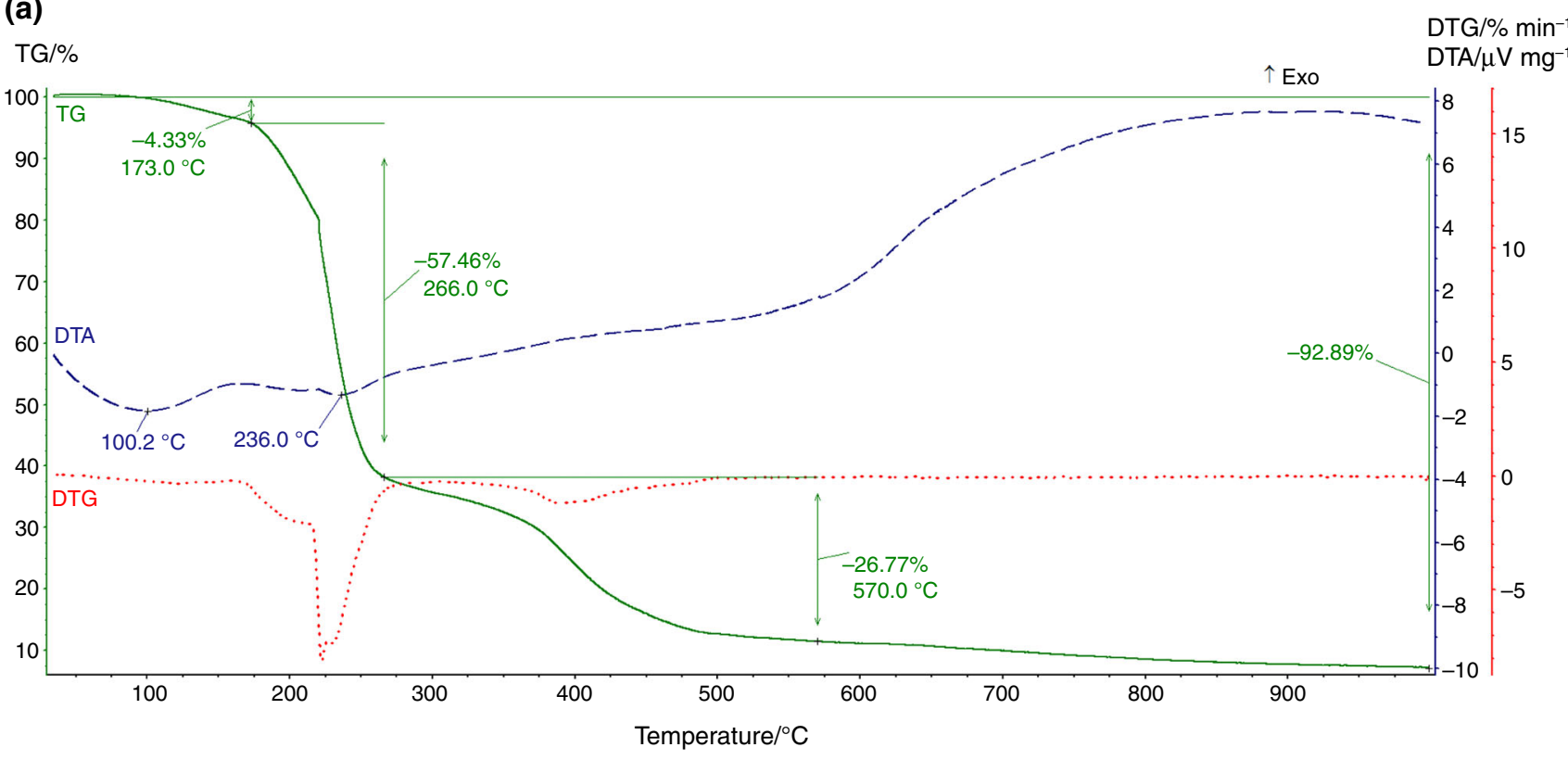

(b)

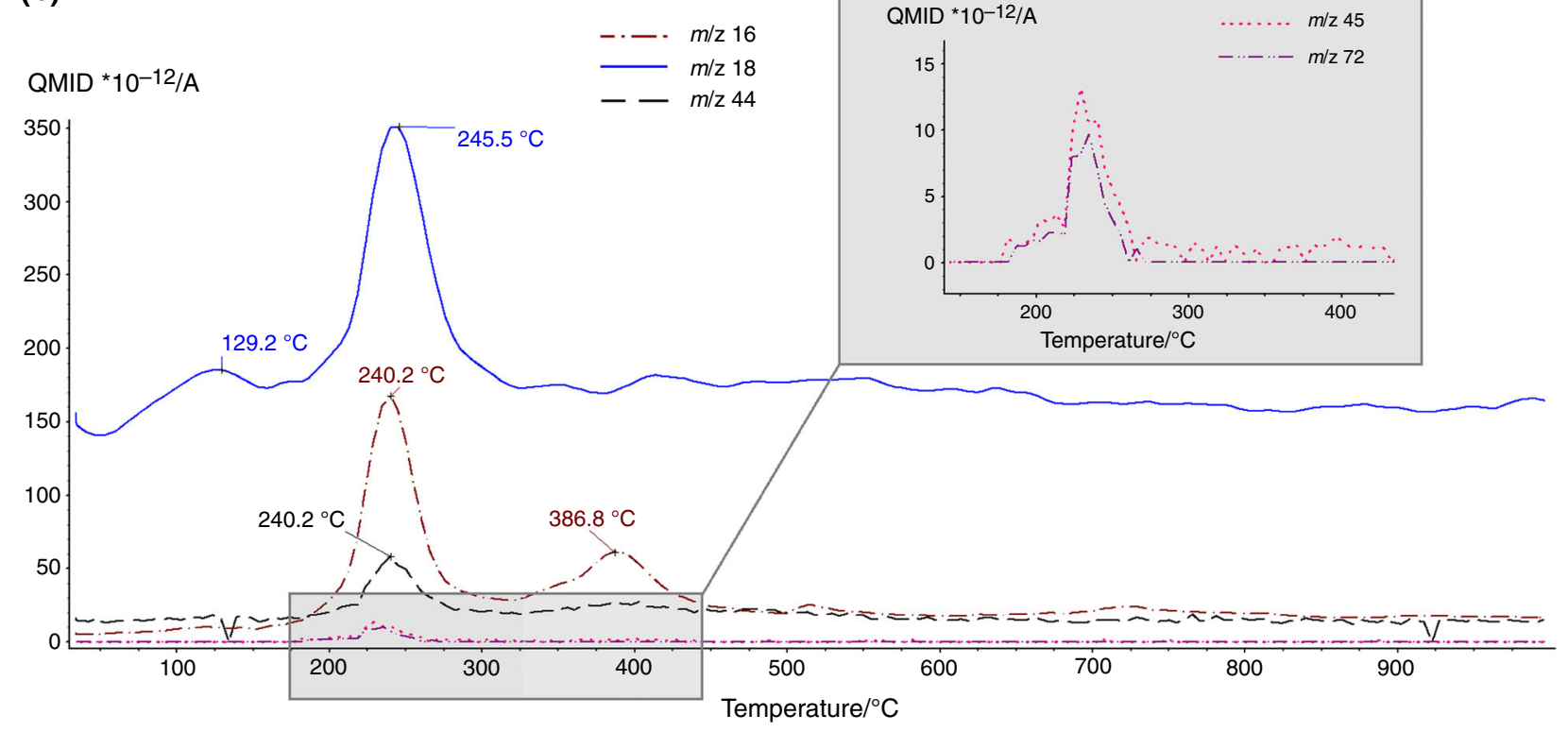

Fig. 2 a DTA/TG/DTG curves of poly(glycerol monoacrylate) registered in non-oxidizing atmosphere (argon); b data from the mass spectrometer coupled with TG

mass increase can be ascribed to the oxidation of $\mathrm{Ni}$ as described elsewhere [35]. The mass spectrometer has detected five $\mathrm{m} / \mathrm{z}$ values: $18,44,45,46$, and 52 . Mass 52 can be ascribed to $\mathrm{C} 4$ hydrocarbons. One can observe that the curve corresponding to $\mathrm{m} / \mathrm{z} 18$, having one maximum, is broader that in case of the pure polymer. Additionally, in case of curve corresponding to $\mathrm{m} / \mathrm{z}, 44$ curve, the second maximum at $460.5{ }^{\circ} \mathrm{C}$ is lower than for the pure polymer.

The differences in thermal degradation of pure polymer and polymer in the $\mathrm{Al}_{2} \mathrm{O}_{3}-\mathrm{Ni}$ green body have been observed also for the measurements performed in argon
(Fig. 4). Mass spectrometer has detected $m / z$ values 16,18 , 44 , and 45 as it was in case of the pure polymer; however, mass 72 did not appear. Instead, masses 46 and 56 have been detected. It must be underlined that in both cases the intensities of masses higher than 44 are of very low intensities, and they all refer to low-chain hydrocarbons, and therefore, these slight differences between both spectra can be treated as negligible. Nevertheless, it is worth to indicate that the maxima on curves 16,18 , and 44 appear at different temperatures and have different intensities than in case of pure polymer measured in argon. Mass 16 which 
(a)

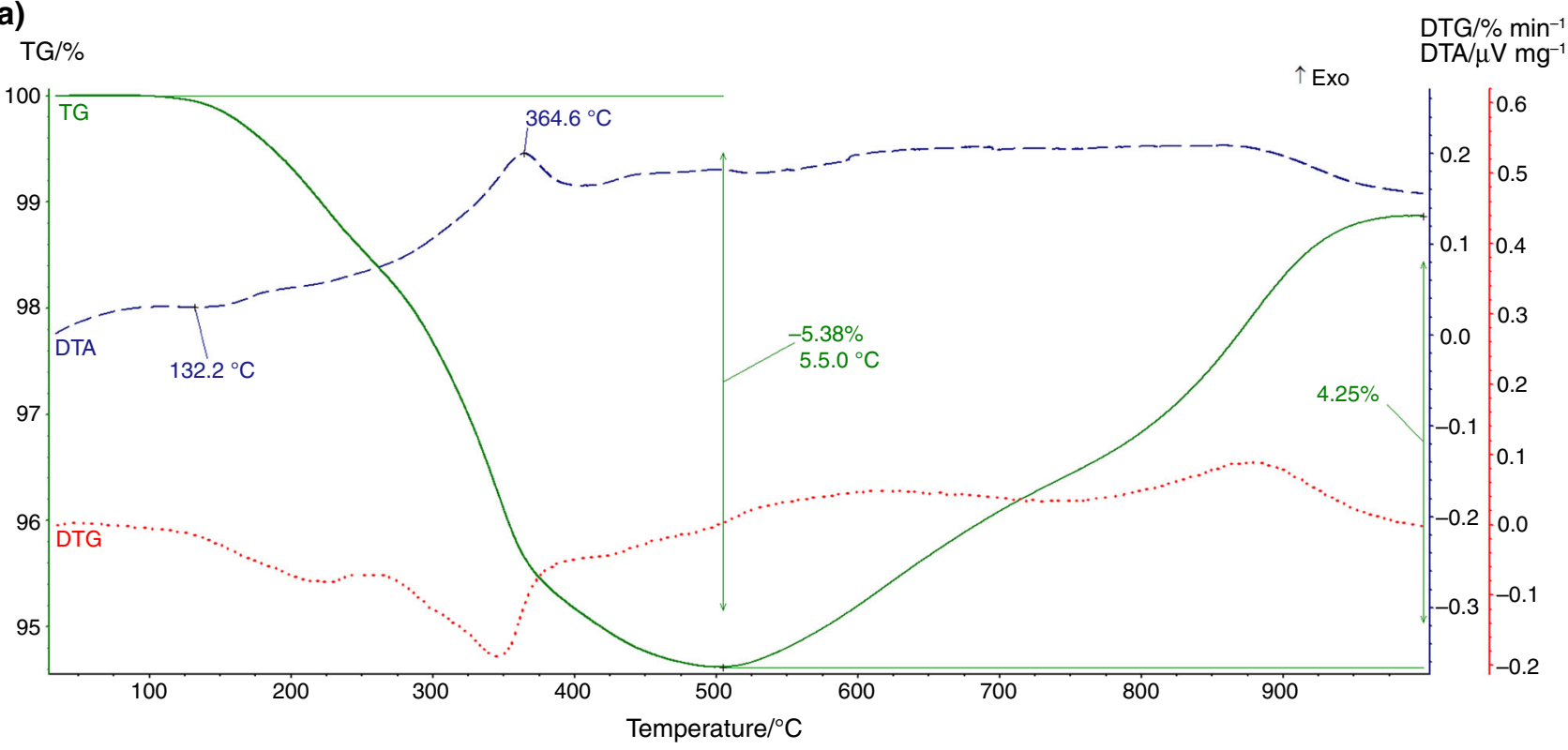

(b)

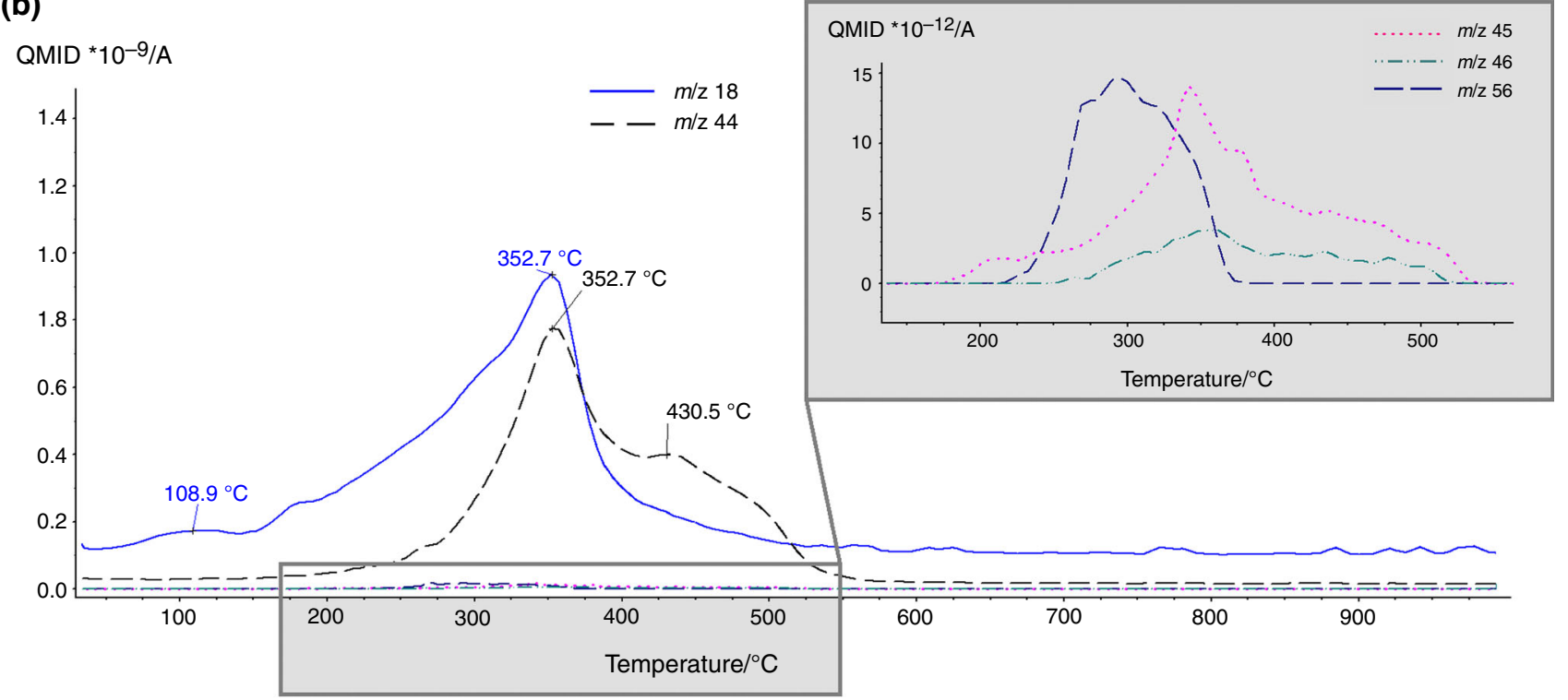

Fig. 3 a DTA/TG/DTG curves of $\mathrm{Al}_{2} \mathrm{O}_{3}-\mathrm{Ni}$ green body obtained by gel-centrifugal casting with the use of glycerol monoacrylate as a monomer, data registered in oxidizing atmosphere (air); $\mathbf{b}$ data from the mass spectrometer coupled with TG

may refer to $\mathrm{O}$ is slightly visible, while the main product of organics decomposition seems to be water vapor. One of the explanations of these differences may be the presence of impurities and gasses adsorbed on the ceramic and metallic powders surface [36] which influences the decomposition reaction of the organic substances. As a result, different quantities of decomposition products are observed.

Alumina-nickel composite green body with smooth surface and no visible defects has been obtained by gelcentrifugal casting. It was found that after drying process, the relative density of green bodies was
$62.25 \pm 0.76 \%$. After the sintering process, the relative density was about $98.31 \pm 0.53 \%$. It means that the prepared composites are described by high degree of packing of the grains in the sintered bodies. The XRD patterns of alumina and nickel powders as well as sintered composite sample are shown in Fig. 5. In case of powders their high purity has been confirmed, only nickel and alumina phases were identified. After the sintering process, no new phase has been created. The use of reducing atmosphere prevents the oxidation of the metal powder, and as a result, only two-phase composite structure has been obtained. 
(a)

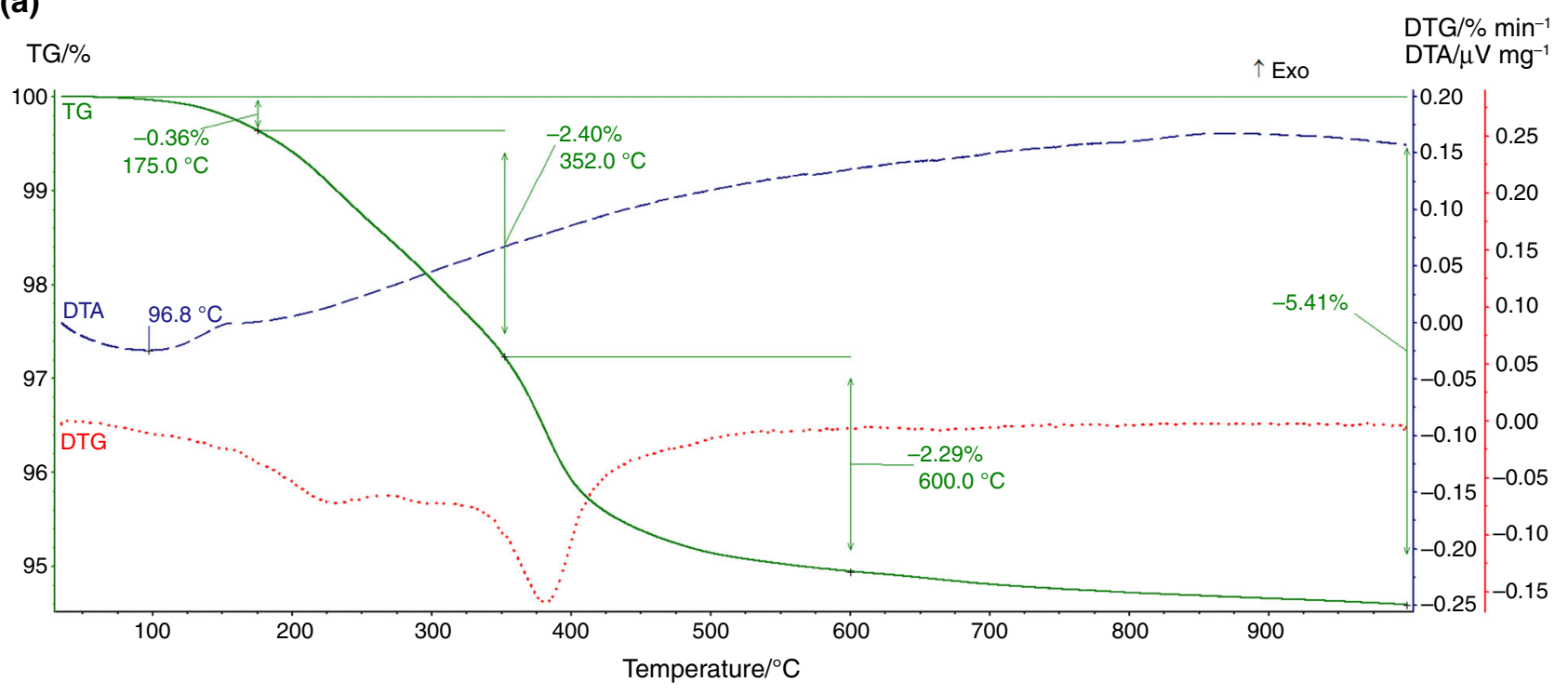

(b)

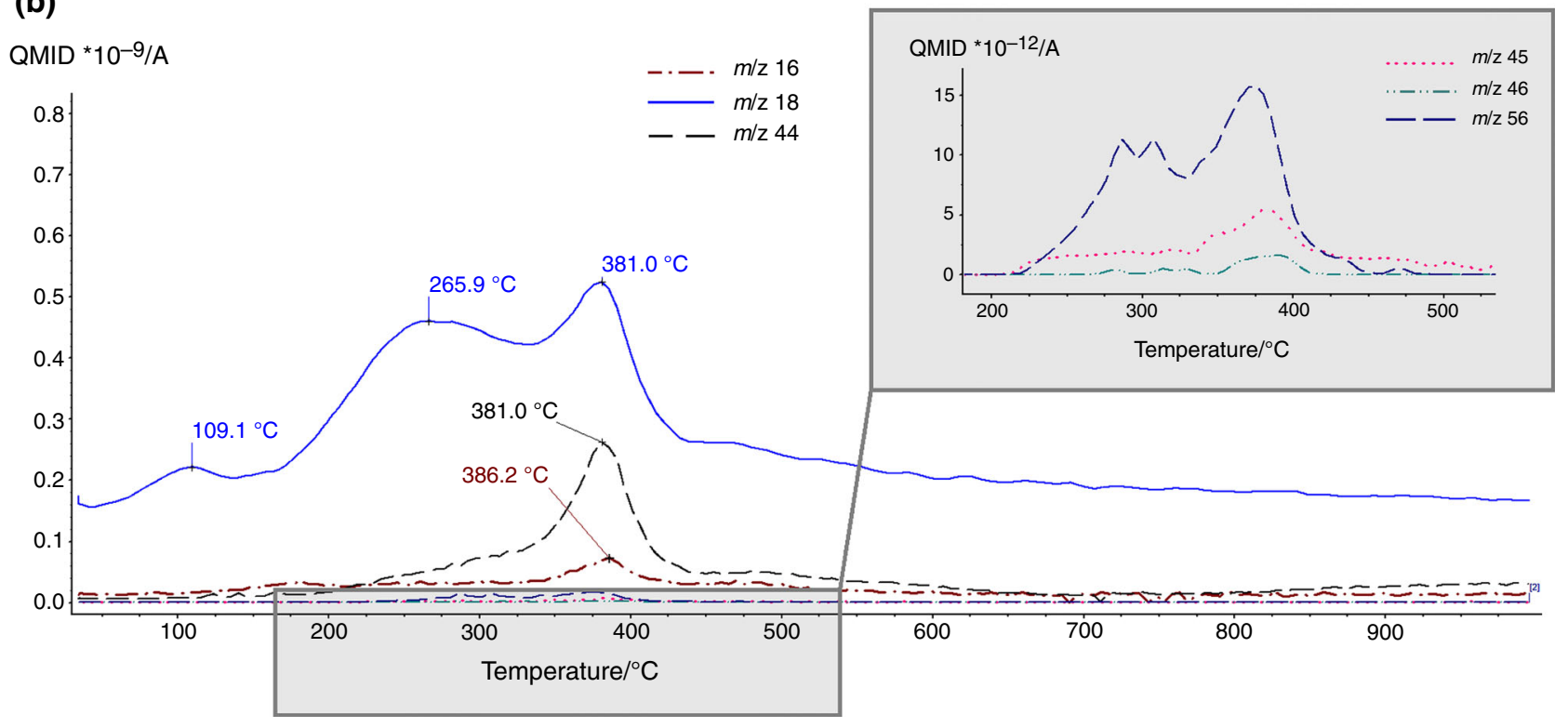

Fig. 4 a DTA/TG/DTG curves of $\mathrm{Al}_{2} \mathrm{O}_{3}-\mathrm{Ni}$ green body obtained by gel-centrifugal casting with the use of glycerol monoacrylate as a monomer, data registered in non-oxidizing atmosphere (argon); b data from the mass spectrometer coupled with TG

The fracture surface of green bodies and sintered samples as observed from SEM is presented in Fig. 6. It is visible that alumina particles were uniformly packed and large pores were observed (Fig. 6a). Furthermore, the ceramic particles closely covered metallic particles which can facilitate the sintering process. For sintered sample (Fig. 6b), the fracture mode was mainly intergranular. At the $\mathrm{Al}_{2} \mathrm{O}_{3}-\mathrm{Ni}$ interface, no cracks or delamination was observed. That may indicate a good bonding between phases. Moreover, in alumina matrix, pores were not observed. The average grain size of $\mathrm{Al}_{2} \mathrm{O}_{3}$ was approximately $1 \mu \mathrm{m}$.
The typical microstructure of the $\mathrm{Al}_{2} \mathrm{O}_{3}-\mathrm{Ni}$ composites obtained by gel-centrifugal casting is presented in Fig. 7 . The gray area is $\mathrm{Al}_{2} \mathrm{O}_{3}$ and the bright area is $\mathrm{Ni}$. The changes in microstructure are represented by three zones. The concentration of nickel decreases from Zone I to Zone II that is from the inner to the outer part of the final sample.

The stereological analysis confirmed that the $\mathrm{Ni}$ grains are distributed in the $\mathrm{Al}_{2} \mathrm{O}_{3}-\mathrm{Ni}$ composites in a gradient way. Figure 8 shows the histograms of changes in nickel content in $\mathrm{Al}_{2} \mathrm{O}_{3}-\mathrm{Ni}$ composite. The maximum amount of nickel was observed in the outer region of the composite (Zone I). The measurements showed that in Zone I, the 
Fig. 5 XRD patterns of nickel and alumina powders and $\mathrm{Al}_{2} \mathrm{O}_{3}-\mathrm{Ni}$ composite

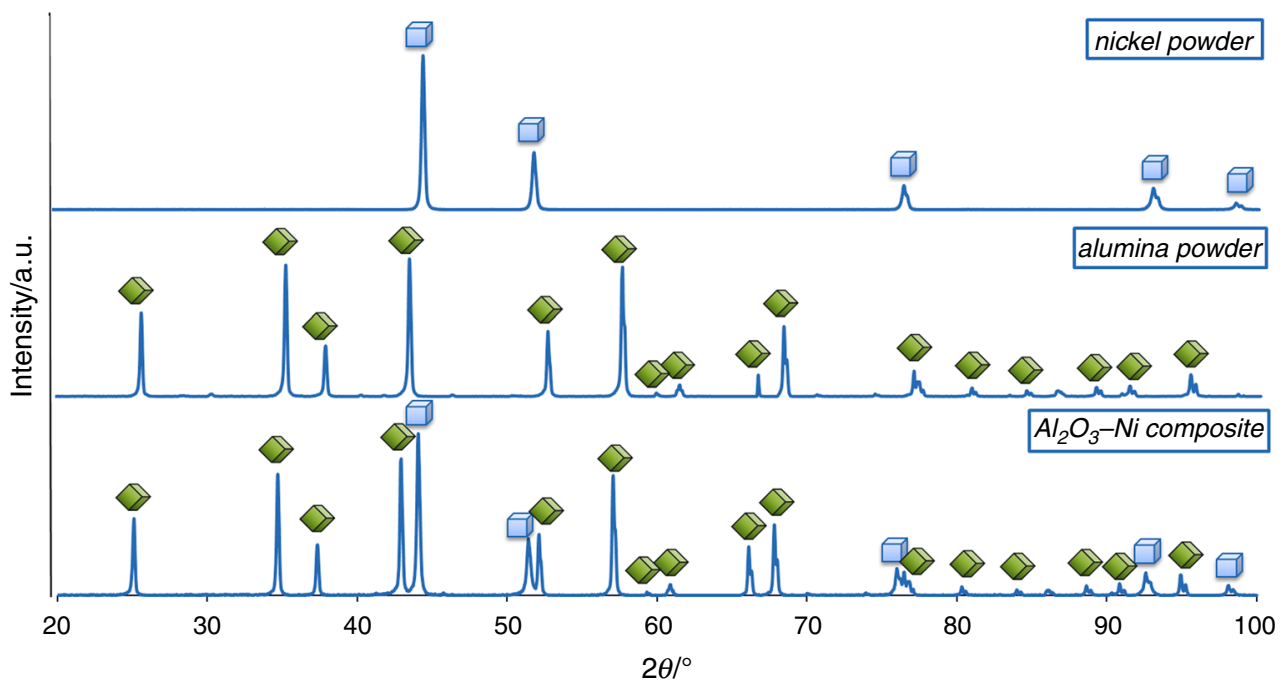

nickel content was 22.5 vol\% per $0.75 \mathrm{~mm}$ sample width. It was confirmed that the content of the nickel particles decreases with the increasing distance from the outer edge to the inside part of the sample. In Zone II nickel content is in the range of $15-7$ vol $\%$ per $0.9 \mathrm{~mm}$. The transition between zones I and II has sharp, stepwise character. In Zone III, mild decrease in nickel concentration was observed. The nickel content falls from 5 to 0 vol\% per $1.2 \mathrm{~mm}$.

The Vickers hardness measurements were made on the polished surfaces of $\mathrm{Al}_{2} \mathrm{O}_{3}-\mathrm{Ni}$ samples. Figure 9 shows the hardness of the samples as a function of the distance from the outer to the inner surface of the sample. The lowest hardness $(7.09 \pm 1.25 \mathrm{GPa})$ were noticed in Zone I due to the maximum concentration of nickel particles in FGM

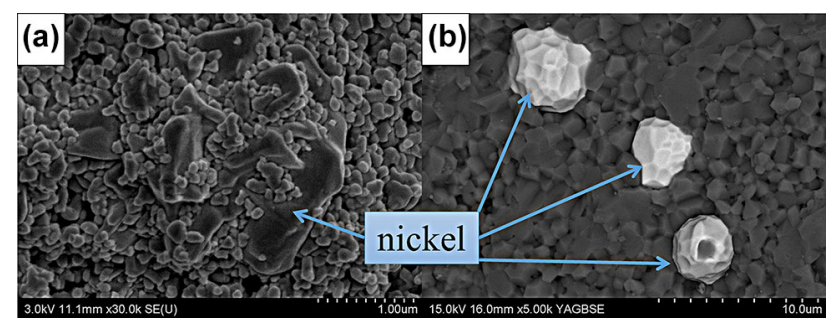

Fig. 6 SEM micrographs of fracture surface of $\mathrm{Al}_{2} \mathrm{O}_{3}-\mathrm{Ni}$ composite obtained by gel-centrifugal casting a green body, $\mathbf{b}$ sintered sample

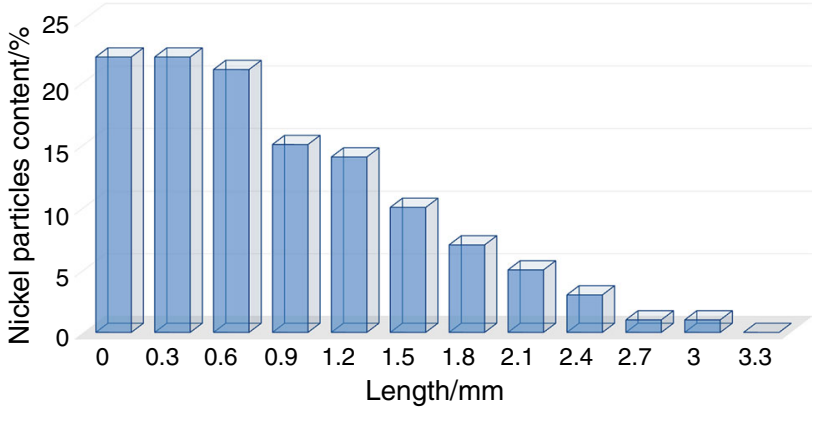

Fig. 8 Changes in nickel content in $\mathrm{Al}_{2} \mathrm{O}_{3}-\mathrm{Ni}$ gradient composite samples (from outer to inner zone of the sample)

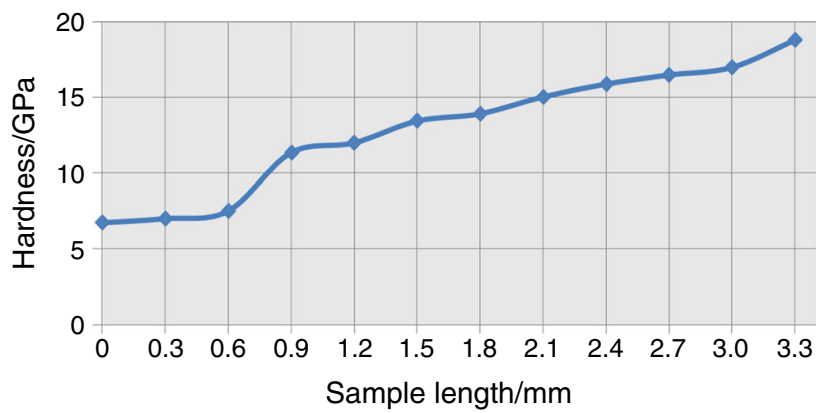

Fig. 9 Changes in $\mathrm{Al}_{2} \mathrm{O}_{3}-\mathrm{Ni}$ composites hardness from outer to inner zone

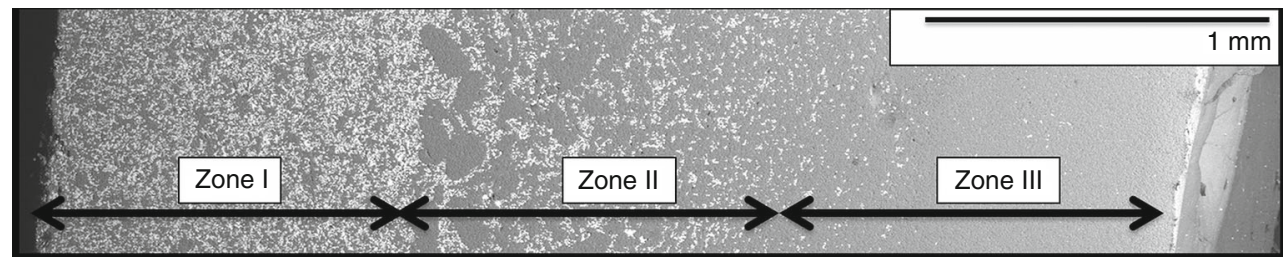

Fig. 7 Typical microstructure of the $\mathrm{Al}_{2} \mathrm{O}_{3}-\mathrm{Ni}$ composite obtained by gel-centrifugal casting 
material. The Zone II was characterized by hardness of $13.16 \pm 1.35 \mathrm{GPa}$. The highest hardness was obtained at the outer edge of Zone III (17.05 $\pm 1.24 \mathrm{GPa})$ what corresponds to the areas without nickel.

\section{Conclusions}

$\mathrm{Al}_{2} \mathrm{O}_{3}-\mathrm{Ni}$-graded hollow tubes were successfully obtained by the gel-centrifugal casting. No additional phases were present when sintering was carried out at $1400{ }^{\circ} \mathrm{C}$ in the reducing atmosphere $\left(\mathrm{H}_{2} / \mathrm{Ar}\right)$. Microstructural observation showed linear gradation of nickel content along the radial direction of samples. Measured Vickers hardness reveal that the relative $\mathrm{Ni}$ content decreased monotonously from the outer toward inner side of the sample.

According to TG/DTA/MS measurements, it can be concluded that thermal degradation of poly(glycerol monoacrylate), used in the process as the binder, proceeds a little faster in non-oxidizing (argon) than in oxidizing atmosphere. However, slight amounts of carbon residues have been observed in case of measurements performed in argon. The main decomposition products are water vapor, carbon dioxide, oxide (observed only for measurements in argon), and small quantities of low-chain hydrocarbons. The presence of $\mathrm{Al}_{2} \mathrm{O}_{3}$ and $\mathrm{Ni}$ powders changes decomposition characteristics of the polymer but mainly toward the changes in the relative quantities of released gasses.

Acknowledgements The results presented in this paper were obtained within the project from the National Science Centre of Poland (NCN), Agreement No. 2013/11/B/ST8/00296.

Open Access This article is distributed under the terms of the Creative Commons Attribution 4.0 International License (http://crea tivecommons.org/licenses/by/4.0/), which permits unrestricted use, distribution, and reproduction in any medium, provided you give appropriate credit to the original author(s) and the source, provide a link to the Creative Commons license, and indicate if changes were made.

\section{References}

1. Lewis JA. Colloidal processing of ceramics. J Am Ceram Soc. 2000;83:2341-59. doi:10.1111/j.1151-2916.2000.tb01560.x.

2. Wiecinska P, Graule T, Bachonko M. Organic additives in geltape casting of ceramic powders: novel approach to the problem of elasticity and cracking of thin tapes. J Eur Ceram Soc. 2015;35:3949-57. doi:10.1016/j.jeurceramsoc.2015.05.028.

3. Sanchez-Salcedo S, Werner J, Vallet-Regi M. Hierarchical pore structure of calcium phosphate scaffolds by a combination of gelcasting and multiple tape-casting methods. Acta Biomater. 2008;4:913-22. doi:10.1016/j.actbio.2008.02.005.

4. Omatete OO, Janney MA, Nunn S. Gelcasting: from laboratory development toward industrial production. J Eur Ceram Soc. 1997;17(2-3):407-13. doi:10.1016/S0955-2219(96)00147-1.
5. Yang J, Yu J, Huang Y. Recent developments in gelcasting of ceramics. J Eur Ceram Soc. 2011;31(14):2569-91. doi:10.1016/j. jeurceramsoc.2010.12.035.

6. Tallon C, Franks GV. Recent trends in shape forming from colloidal processing: a review. J Ceram Soc Jpn. 2011;119(1387): 147-60. doi:10.2109/jcersj2.119.147.

7. Young AC, et al. Gelcasting of alumina. J Am Ceram Soc. 1991;74(3):612-8.

8. Huan Y, Yang J. Novel colloidal forming of ceramics. Beijing: Tsinghua University Press; 2010.

9. Potoczek M, Zawadzak E. Initiator effect on the gelcasting properties of alumina in the system involving low-toxic monomers. Ceram Int. 2004;30:793-9. doi:10.1016/j.ceramint.2003.09.014.

10. Nieto MI, Suarez I, Moreno R. Shaping of dense advanced ceramics and coatings by gelation of polysaccharides. Adv Eng Mater. 2014;16:637-54. doi:10.1002/adem.201400076.

11. Li Y, Guo Z, Hao J, Ren S. Gelcasting of metal powders in nontoxic cellulose ethers system. J Mater Process Technol. 2008;208:457-62. doi:10.1016/j.jmatprotec.2008.01.009.

12. Zhang C, Qiu T, Yang J, Guo J. The effect of solid volume fraction on the properties of ZTA composites by gelcasting using DMAA system. Mater Sci Eng, A. 2012;30:243-9. doi:10.1016/j. msea.2012.01.090.

13. Miazga A, Konopka K, Gizowska M, Szafran M. Preparation of $\mathrm{Al}_{2} \mathrm{O}_{3}-\mathrm{Ni}$ cermet composites by aqueous gelcasting. Powder Metall Met Ceram. 2014;52:567-71. doi:10.1007/s11106-0149561-y.

14. Oziębło A, Konopka K, Bobryk E, Szafran M, Kurzydłowski KJ. $\mathrm{Al}_{2} \mathrm{O}_{3}-\mathrm{Fe}$ functionally graded materials fabricated under magnetic field. Solid State Phenom. 2005;101-102:143-6. doi:10. 4028/www.scientific.net/SSP.101-102.143.

15. Zygmuntowicz J, Miazga A, Konopka K, Jedrysiak K, Kaszuwara W. Alumina matrix ceramic-nickel composites formed by centrifugal slip casting. Process Appl Ceram. 2015;9:199-202. doi:10.2298/PAC1504199Z.

16. Zhu X, Xu J, Meng Z. Interdiffusion reaction in the PZT/PNN fuctionally gradient piezoelectric ceramic materials. J Mater Sci. 1998;33:1023-30.

17. Santacruz I, Ferrari B, Nieto MI, Moreno R. Graded ceramic coatings produced by thermogelation of polysaccharides. Mater Lett. 2004;58:2579-82. doi:10.1016/j.matlet.2004.03.017.

18. Zygmuntowicz J, Wiecinska P, Miazga A, Konopka K, Kaszuwara W. $\mathrm{Al}_{2} \mathrm{O}_{3} / \mathrm{Ni}$ functionally graded materials (FGM) obtained by centrifugal-slip casting method. J Therm Anal Calorim. 2017; . doi:10.1007/s10973-017-6232-5.

19. Zygmuntowicz J, Miazga A, Konopka K, Kaszuwara W. Structural and mechanical properties of graded composites $\mathrm{Al}_{2} \mathrm{O}_{3} / \mathrm{Ni}$ obtained from slurry of different solid content. Struct Integirty Procedia. 2016;1:305-12. doi:10.1016/j.prostr.2016.02.041.

20. Zygmuntowicz J, Miazga A, Konopka K, Kaszuwara W. Metal particles size influence on graded structure in composite $\mathrm{Al}_{2} \mathrm{O}_{3}-$ Ni. Mater Technol. 2016;50:537-41. doi:10.17222/mit.2015.120.

21. Sato K, Hotta Y, Yilmaz H, Watari K. Fabrication of green and sintered bodies prepared by centrifugal process using wet-jet milled slurries. J Eur Ceram Soc. 2009;29:1323-9. doi:10.1016/j. jeurceramsoc.2008.08.026.

22. Maleksaeedi S, Paydar MH, Ma J. Centrifugal dearing of concentrated ceramic slurries. J Am Ceram Soc. 2009;92(12): 2861-9.

23. Huisman W, Graule T, Gauckler LJ. Alumina of high reliability by centrifugal casting. J Eur Ceram Soc. 1995;15:811-21. doi:10. 1016/0955-2219(95)00053-W.

24. Gizowska M, Konopka K, Szafran M. Properties of water-based slurries for fabrication of ceramic-metal composites by slip casting method. Arch Metall Mater. 2011;56:1105-10. doi:10. 2478/v10172-011-0123-8. 
25. Hidber PC, Graule TJ, Gauckler LJ. Citric acid: a dispersant for aqueous alumina suspensions. J Am Ceram Soc. 1996;79(7):1857-67. doi:10.1111/j.1151-2916.1996.tb08006.x.

26. Tallon C, Jach D, Moreno R, Nieto MI, Rokicki G, Szafran M. Gelcasting of alumina suspensions containing nanoparticles with glycerol monoacrylate. J Eur Ceram Soc. 2009;29:875-80. doi:10.1016/j.jeurceramsoc.2008.07.014.

27. Michalski J, Wejrzanowski T, Pielaszek R, Konopka K, Łojkowski W, Kurzydłowski KJ. Application of image analysis for characterization of powders. Mater Sci Poland. 2005;23(1):79-86.

28. Mikli V, Kaerdi H, Kulu P, Besterci M. Characterization of powder particle morphology. Proc Estonian Acad Sci Eng. 2001;7(1):22-34

29. Golofit T, Zysk K. Thermal decomposition properties and compatibility of CL-20 with binders HTPB, PBAN, GAP and polyNIMMO. J Therm Anal Calorim. 2015;119:19319.

30. Sczygiel I, Winiarska K. Synthesis and characterization of manganesezinc ferrite obtained by thermal decomposition from organic precursors. J Therm Anal Calorim. 2014;115:4717.

31. Etienne S, Becker C, Ruch D, Germain A, Calberg C. Synergetic effect of poly(vinyl butyral) and calcium carbonate on thermal stability of poly(vinyl chloride) nanocomposites investigated by TG-FTIR-MS. J Thermal Anal Calorim. 2010;100:667-77.
32. Czylkowska A, Raducka A, Mierczynski P. Synthesis, thermal study and some properties of $\mathrm{Zn}(\mathrm{II}), \mathrm{Cd}(\mathrm{II})$ and $\mathrm{Pb}(\mathrm{II})$ compounds with mono-, di- and trichloroacetates. J Therm Anal Calorim. 2017;128:937-46. doi:10.1007/s10973-016-5940-6.

33. Wiecinska P. Thermal degradation of organic additives used in colloidal shaping of ceramics investigated by the coupled DTA/ TG/MS analysis. J Therm Anal Calorim. 2016;123:1419-30. doi:10.1007/s10973-015-5075-1.

34. Wiecinska P, Bachonko M. Processing of porous ceramics from highly concentrated suspensions by foaming, in situ polymerization and burnout of polylactide fibers. Ceram Int. 2016;42:15057-64. doi:10.1016/j.ceramint.2016.06.162.

35. Zygmuntowicz J, Wiecinska P, Miazga A, Konopka K. Characterization of composites containing $\mathrm{NiAl}_{2} \mathrm{O}_{4}$ spinel phase from $\mathrm{Al}_{2} \mathrm{O}_{3} / \mathrm{NiO}$ and $\mathrm{Al}_{2} \mathrm{O}_{3} / \mathrm{Ni}$ systems. $\mathrm{J}$ Therm Anal Calorim. 2016;125:1079-86. doi:10.1007/s10973-016-5357-2.

36. Danelska A, Ulkowska U, Socha RP, Szafran M. Surface properties of nanozirconia and their effect on its rheological behaviour and sinterability. J Eur Ceram Soc. 2013;33:1875-83. 